\title{
Preface of the Editors
}

The ninth volume of the Series "Advances in Systems, Signals and Devices" (ASSD), is dedicated to fields related to "Systems, Automation and Control" (SAC). The scope of this issue encompasses all aspects of the research, development and applications of the science and technology in these fields.

Topics of this issue concerns: system design, systemidentification, biological and economical models \& control, modern control theory, nonlinear observers, control and application of chaos, adaptive/non-adaptive backstepping control techniques, advances in linear control theory, system optimization, multivariable control, large scale and infinite dimension systems, nonlinear control, distributed control, predictive control, geometric control, adaptive control, optimal and stochastic control, robust control, neural control, fuzzy control, intelligent control systems, diagnostics, fault tolerant control, robotics and mechatronics, navigation, robotics and humanmachine interaction, hierarchical and man-machine systems, etc.

Authors are encouraged to submit novel contributions which include results of research or experimental work discussing new developments in the field of systems, automation and control. The journal can be also addressed for editing special issues for novel developments in specific fields. Guest editors are encouraged to make proposals to the editor in chief of the corresponding main field.

The aims of this volume, in its own way, to promote an international scientific progress in the fields of systems, automation and control. It provides at the same time an opportunity to be informed about interesting results that have been reported during the international SSD conferences.

The Editors

Nabil Derbel, Faouzi Derbel and Olfa Kanoun 
